\section{Cureus}

Received 10/31/2015

Review began 11/03/2015

Review ended 11/13/2015

Published 12/03/2015

\section{(c) Copyright 2015}

Bhatti et al. This is an open access article distributed under the terms of the Creative Commons Attribution License CC-BY 3.0., which permits unrestricted use, distribution, and reproduction in any medium, provided the original author and source are credited.

\title{
Drug Targets for Oxidative Podocyte Injury in Diabetic Nephropathy
}

\author{
Adnan Bashir Bhatti ${ }^{1}$, Muhammad Usman ${ }^{2}$ \\ 1. Medical Director of Clinical Research, Spine Surgery, Tristate Brain and Spine Institute, United States, \\ Atlanta, USA 2. Department of Medicine, Jinnah Hospital Lahore (JHL)/Allama Iqbal Medical College \\ (AIMC), Lahore, Pakistan
}

$\square$ Corresponding author: Adnan Bashir Bhatti, dr.adnanbashir@gmail.com Disclosures can be found in Additional Information at the end of the article

\section{Abstract}

Diabetic nephropathy (DN) is one the most prevalent chronic complications of diabetes mellitus that affects as much as one-third of diabetic patients irrespective of the type of diabetes. Hyperglycemia is the key trigger for DN that initiates a number of microscopic and ultramicroscopic changes in kidney architecture. Microscopic changes include thickening of the glomerular basement membrane (GBM), tubular basement membrane (TBM), mesangial proliferation, arteriosclerosis, and glomerulotubular junction abnormalities (GTJA). Among the ultramicroscopic changes, effacement of podocytes and decrease in their density seem to be the centerpiece of DN pathogenesis. These changes in kidney architecture then produce functional deficits, such as microalbuminuria and decreased glomerular filtration rate (GFR). Among several mechanisms involved in inflicting damage to podocytes, injuries sustained by increased oxidative stress turns out to be the most important mechanism. Different variables that are included in increased production of reactive oxygen species (ROS) include a hyperglycemia-induced reduction in glutathione (GSH), nicotinamide adenine dinucleotide phosphate (NADPH) oxidase activation via hyperglycemia, advanced glycation end products (AGEs), protein kinase C (PKC), and renin-angiotensin-aldosterone system (RAAS).

Unfortunately, control of podocyte injury hasn't received much attention as a treatment approach for DN. Therefore, this review article is mainly concerned with the exploration of various treatment options that might help in decreasing the podocyte injury, mainly by reducing the level of NADPH oxidase-mediated generation of ROS. This article concludes with a view that certain NADPH oxidase inhibitors, RAAS inhibitors, statins, antidiabetic drugs, and antioxidant vitamins might be useful in decreasing podocyte injury and resultant structural and functional kidney impairments in DN.

Categories: Endocrinology/Diabetes/Metabolism, Internal Medicine, Nephrology

Keywords: diabetes, diabetic nephropathy, oxidative podocyte injury, oxidative stress, hyperglycemia

\section{Introduction And Background}

Diabetes is a group of metabolic disorders that is characterized by persistent hyperglycemia either due to the destruction of beta pancreatic cells resulting in a deficit in insulin production or decreased responsiveness of body tissues to secreted insulin (or decreased insulin sensitivity), or both [1-2]. As per 2014 estimates, the global prevalence of diabetes was $8.3 \%$, affecting more than 387 million adults worldwide. These figures are expected to rise to as much as $55 \%$ by the end of the year 2030, which will affect more than 592 million adults [3]. The following figure depicts the latest statistics of diabetics worldwide (Figure 1). 


\section{Cureus}

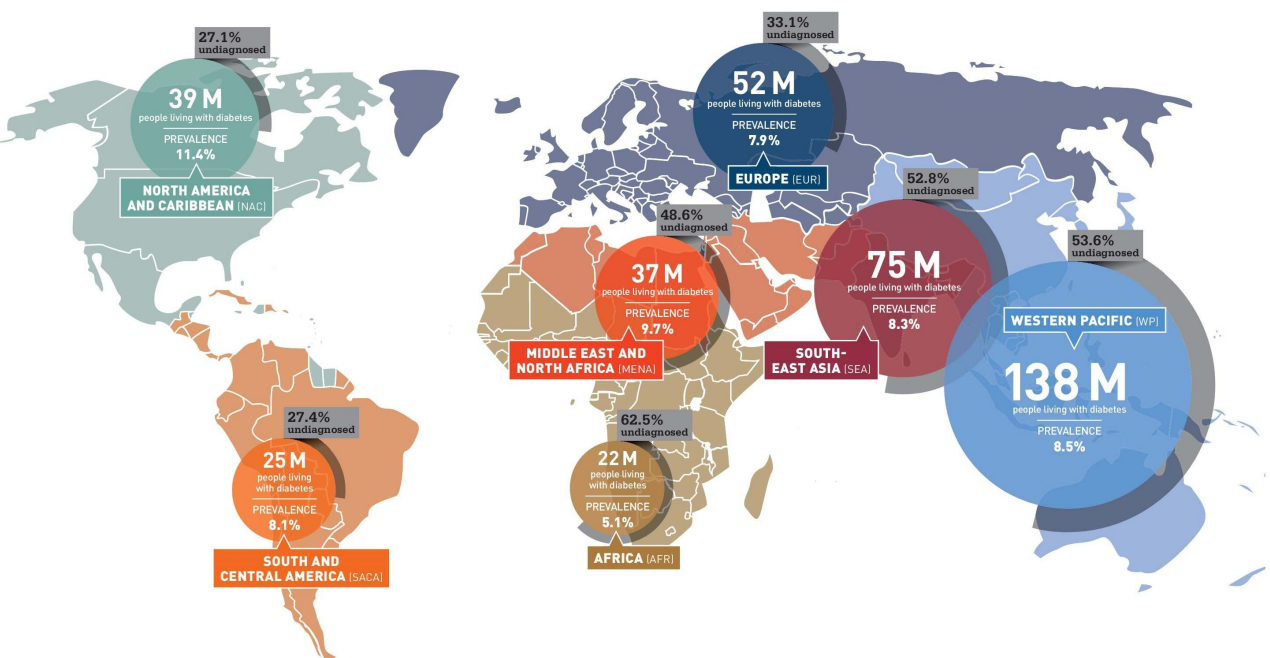

\section{FIGURE 1: Prevalence of Diabetes. Figure adapted from the diabetes atlas published by International Diabetes Federation (IDF).}

Retrieved from IDF website on November 12, 2015: http://www.idf.org/sites/default/files/Atlasposter-2014_EN.pdf

Poor glycemic control in diabetes not only increases the risk of acute complications, like hypoglycemia and hyperglycemia [4], but is also responsible for longstanding (chronic) diabetic complications [5]. Long-term complications of diabetes include diabetic nephropathy, peripheral diabetic neuropathy, diabetic retinopathy, autonomic diabetic neuropathy, and cardiovascular complications, such as heart attack and stroke [1, 5-8]. Among these chronic complications, diabetic nephropathy (DN) seems to be the most prevalent as it affects as much as one-third of diabetics irrespective of the type of diabetes they suffer from [9-10]. DN can have fatal consequences that are mostly secondary to kidney failure and cardiovascular complications [11-12]. Therefore, knowing different aspects of DN progression and drug targets can help improve morbidity and mortality status in such patients.

The gross microscopic picture of DN is characterized by increased thickening of glomerular basement membrane (GBM), which is perhaps the earliest detectable lesion in DN [13-14]. As the disease progresses, the thickening of the tubular basement membrane (TBM) soon follows GBM thickening [15]. Thereafter, different degrees of mesangial expansion, which is mainly due to the increased deposition of mesangial matrix and mesangial cellular proliferation, significantly compromises the surface area of the glomerulus that is available for filtration [13, 16-17]. Hyalinosis of afferent and efferent arterioles develops a few years after the initial onset of the disease [18]. Various degrees of glomerulotubular junction abnormalities (GTJA), such as adhesions and obstruction of proximal convoluted tubules, are seen in the later stages of the disease [18-19]. The eventual outcomes of DN include significant atrophy of tubules, focal or segmental glomerulosclerosis, expansion of mesangium and GTJA, which then leads to functional abnormalities like a significant reduction in glomerular filtration rate (GFR) and proteinuria [20-21].

DN in humans is characterized by microalbuminuria, which eventually can progress to proteinuria [22]. Changes in GBM represent an important cause of microalbuminuria; however, 
a detailed analysis of renal biopsies from patients with Type I and Type II diabetes has demonstrated damage to the cellular elements of the renal glomeruli, which includes visceral epithelial cells and podocytes, as important predictors of functional abnormalities in DN [2324]. Damage to podocytes represents a significant yet undermined pathological lesion of DN. Analysis of kidney specimens from biopsies of patients with diabetes has shown a marked reduction in the density of podocytes, which was not only evident in patients with advanced disease but was also present in patients with short-term diabetes without microalbuminuria [25-26]. Moreover, experimental models of Type I and Type II diabetes have proved the relevance of podocyte injury in diabetes where depletion of podocytes was found to be the earliest cellular anomaly in DN [27-28]. The relevance of podocyte injury with DN is wellestablished [29], but what causes this injury is still not completely understood and is a matter of ongoing research.

Hyperglycemia seems to be the centerpiece for podocyte injury and DN as a whole, which is most likely due to a higher degree of oxidative stress. Excess glucose is metabolized through multiple accessory pathways like the polyol pathway that converts glucose into sorbitol, which then depletes the amount of antioxidants like glutathione (GSH), and increases the level of reactive oxygen species (ROS) [30]. In addition, increased blood glucose undergoes condensation with free amino acids to form advanced glycation end products (AGEs), which then modulates several important events like the induction of protein kinase C (PKC) [31] and generation of ROS via AGE/a receptor for AGE (RAGE) axis activated nicotinamide adenine dinucleotide phosphate (NADPH) oxidase [32]. Among kinase signaling pathways, the most commonly activated pathway includes the PKC pathway [33], which then triggers the production of ROS via NADPH oxidase [34]. All these pathways are somewhat interlinked, i.e. AGEs and PKC increase the oxidative stress and oxidative stress in turn exacerbates the generation of AGEs and PKC [35-37] (Figure 2). 


\section{Cureus}

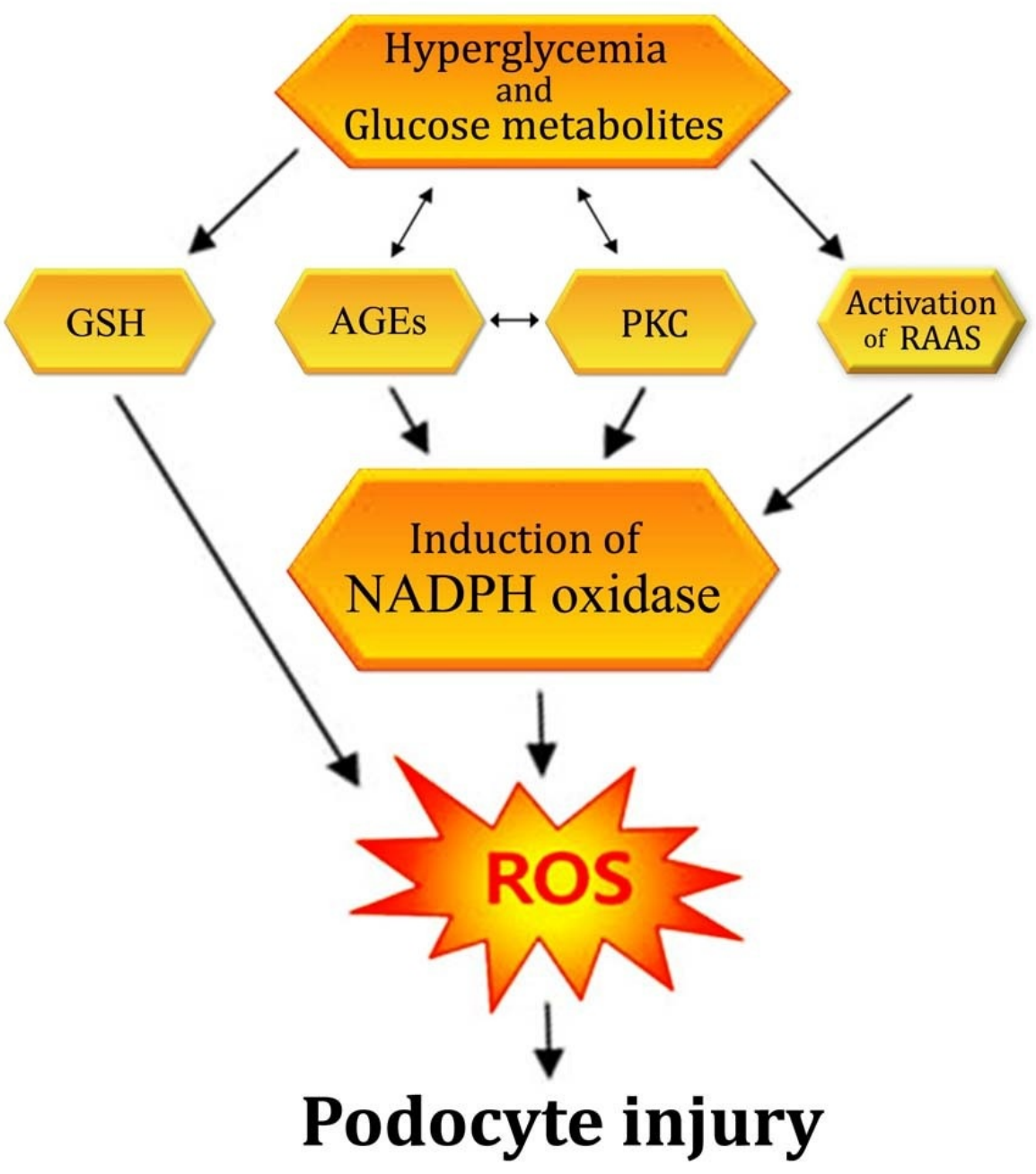

\section{FIGURE 2: Mechanism of increase in oxidative stress and resultant podocyte injury due to hyperglycemia.}

High glucose gets metabolized to form obnoxious glucose metabolites; directly reduces the quantity of antioxidants like glutathione (GSH); fuses with proteins to form advanced glycation end products (AGEs); induces protein kinase C (PKC) signaling and deranges renin-angiotensin-aldosterone system (RAAS). All these mechanism tend to increase oxidative stress by inducing the action of NADPH oxidase. The reactive oxygen species (ROS), thus produced, inflict injury to podocytes and decrease their density.

A significantly important limb responsible for oxidative stress-induced podocyte damage is the renin-angiotensin-aldosterone axis. Hyperglycemia causes a local increase in blood pressure due to the activation of the renin-angiotensin system (RAS) [38]. In addition, podocytes express functional renin-angiotensin-aldosterone system (RAAS), which includes the angiotensinconverting enzyme (ACE), prorenin receptors (PRR), mineralocorticoid receptors (MR), neprilysin, aminopeptidase A, and renin [39-40]. Studies have demonstrated that activation of angiotensin type 1 receptors (AT1R) by angiotensin II leads to agglomeration of oxidative stress in podocytes during DN [41]. The basic culprit behind RAAS-induced podocyte injury, as shown by studies, is NADPH oxidase [42]. 
So the question is how the generation of ROS causes damage to podocytes; ROS are well known for their potential to induce apoptosis in cells [43]. Normally, a small amount of ROS is rather essential in maintaining normal cell hemostasis, but hyperglycemia induces production of excessive ROS that results in tissue damage [36]. NADPH oxidase-mediated ROS rise seems to play a fundamental role in podocyte injury in DN. It was demonstrated that in cultured human podocytes, ROS was primarily generated by the NADPH oxidase-mediated pathway, and the podocytes additionally showed the overexpression of NADPH oxidase subunits [44]. The oxidative stress, which is the consequence of the overactivity of NADPH oxidase, thereafter causing cell death due to the triggering of a number of abnormal cell processes. These processes primarily include the damage to the cell DNA, activation of mitochondrial proapoptotic factors, and hoarding of aberrant proteins [45-46].

In a crux, it is evident from the above discussion that hyperglycemia-induced oxidative stress is the key event in the injury inflicted to podocytes in DN. Therefore, improvement in our understanding of oxidative stress may prove to be the missing key in the pathogenesis of DN. Moreover, drug targets that can help improve the degree of podocyte survival by decreasing oxidative stress can prove to be valuable assets in treating diabetic patients with DN. Therefore, the purpose of this article is to find possible drug targets that have been shown to decrease ROS-induced podocyte injury and possibly improve DN status in patients suffering from diabetes mellitus.

\section{Review}

Podocyte injury has been implicated as one of the earliest events in DN. Injury to podocytes due to uncontrolled hyperglycemia and resultant podocyte apoptosis are the most significant events that seem to contribute in decreasing podocyte density, which can be evaluated as microalbuminuria [47]. Diabetes hyperglycemia induces the production of ROS via several mechanisms. NADPH oxidase activation seems to have a pivotal role in all these mechanisms. All of these events then lead to the development of several DN manifestations, including increased podocyte injury [48-50]. Functional loss of kidney structure precedes the loss of podocytes. Therefore, this section is mainly concerned with exploring various therapeutic agents and drug targets that may offer a certain degree of protection to podocytes by decreasing oxidase stress, which may eventually be helpful in treating DN, does not respond well to current treatment options, and has a high morbidity and mortality. The following table summarizes the list of various renoprotective drugs that uphold podocyte architecture (Table 1). 


\section{Cureus}

\begin{tabular}{|c|c|c|}
\hline Group & Drug Name & References \\
\hline \multirow{3}{*}{ NADPH Oxidases Inhibitors } & Triptolide & [52] \\
\hline & Apocynin & [57] \\
\hline & Diphenyleneiodonium (DPI) & [59] \\
\hline \multirow{4}{*}{ RAAS Inhibitors } & Enalapril & [66] \\
\hline & Spironolactone & [69] \\
\hline & Losartan & [70] \\
\hline & ACEls and MR blockers & [71] \\
\hline \multirow{2}{*}{ Statins } & Rosuvastatin & [77] \\
\hline & Pitavastatin & [78] \\
\hline \multirow{2}{*}{ Antidiabetic Drugs } & Rapamycin & [81] \\
\hline & Metformin & [84] \\
\hline Antioxidant Vitamins & Vitamin D & [93] \\
\hline
\end{tabular}

TABLE 1: Overview of renoprotective drugs that uphold podocyte architecture mainly by decreasing oxidative stress.

\section{NADPH oxidase inhibitors}

As discussed above, almost all hyperglycemia-activated pathways induce the production of ROS via the activation of NADPH oxidase. Thus, it can be safely speculated that inhibition of this enzyme may be the most effective therapy in reducing hyperglycemia-induced oxidative stress and resultant podocyte injury. In fact, this hypothesis has been backed by several studies where the use of different oxidase inhibitors has shown significant promise in putting a stop and rather reversing the oxidative stress-mediated podocyte injury. Triptolide is a known antiinflammatory substance and is well-known for its ability to decrease oxidative stress. It brings about its action by causing inhibition of NADPH oxidase and inducible nitric oxide synthase (iNOS) [51]. Treatment or pretreatment of a rat model of DN with triptolide decreased the production of ROS by the deactivation of NADPH oxidase. The kidney functions improved as shown by reduced proteinuria. Use of triptolide actually reversed the structural damage, as observed as the decrease in the effacement of podocyte foot processes [52]. Apocynin, a potent antioxidant [53], seems to help with podocyte injury through several mechanisms. First, it inhibits the action of NADPH oxidase [54-56]. Second, it mitigates the level of oxidative stress by improving the status of antioxidants like renal glutathione [57]. Diphenyleneiodonium (DPI) brings about its antioxidant effect by causing the inhibition of NADPH oxidase [58]. This activity of DPI also protects podocytes from the damage inflicted by NADPH oxidase-generated ROS [59]. In addition, certain substances, such as triazolopyrimidine, GKT136901, and pyrazolopyridine dione derivatives, have been shown to have a variable degree of NADPH oxidase inhibiting activity, but their role in protecting podocyte injury against oxidative stress and improving the structural and functional impairments in DN has not been extensively 
studied thus far [60-62].

\section{Renin-angiotensin-aldosterone system inhibitors}

Angiotensin-converting enzyme inhibitors (ACEIs) and angiotensin receptor inhibitors (ARIs) have long been used for the treatment of both non-diabetic and diabetic kidney diseases. How these drugs help protect patients with kidney disease is still not completely understood and cannot be explained by mere regulation of blood pressure [63-64]. Enalapril is an orally prescribed ACEI [65]. Its use has shown to offer a great degree of renoprotective effects in DN. Researchers have demonstrated the antioxidant activity of enalapril in animal models of DN. The study included 24 rats that were divided into three groups: the first group received streptozotocin, the second group received streptozotocin and enalapril, and the third group received placebo (saline only). After seven months of following the protocol, the rats receiving streptozotocin and enalapril showed improvement in kidney structure and function. Researchers concluded that this effect was largely due to the antioxidant activity of enalapril, which includes its ability to improve glutathione status in the kidney [66]. Spironolactone is a known aldosterone receptor antagonist that has been shown to have antioxidant potential. The antioxidant potential of spironolactone can mainly be attributed to its ability to inhibit NADPH oxidase [67]. In addition, it also up-regulates the amount of antioxidants like superoxide dismutase [68]. Researchers have determined the effects of spironolactone administration in animal models of diabetic nephropathy. They concluded that treatment of diabetic rats with spironolactone inhibited NADPH oxidase activity. Moreover, the resultant podocyte injury also diminished following the reduction in oxidative stress [69]. Another RAAS inhibitor is losartan and its metabolites. Recent studies have shown that the metabolites of losartan, EXP3179, but not losartan itself, downregulate the NADPH oxidase activity and NADPH-mediated production of ROS [70]. This property of losartan may also find a way in the treatment of podocyte injury in DN. Moreover, using a combination of RAAS inhibitor drugs may also be helpful in offering a greater degree of renoprotection in subjects with DN. It was also been demonstrated that using a combination of ACEIs and aldosterone receptor blockers (ARBs) offers a greater degree of renoprotection in patients with diabetic nephropathy by the additive inhibition of NADPH oxidase [71].

\section{Statins}

Statins are antihypercholesterolemic drugs that have beneficial antioxidant activity as well. The antioxidant ability of statins can be attributed to two of their properties. First, they decrease the activity of ROS-producing enzymes, such as NADPH oxidase [72-75]. Second, they also increase the level of antioxidants like catalase [76] and superoxide dismutase [77]. Researchers have demonstrated the effects of rosuvastatin administration on an animal model of diabetic nephropathy. The Zucker obese rats were assessed for different variables like the level of oxidative markers (NADPH oxidase), markers of podocyte injury like the effacement of podocyte foot processes, and loss of kidney function as shown by albuminuria. Results showed that treatment of Zucker obese rats with rosuvastatin improved albuminuria, improved the integrity of podocyte filtration barrier, and reduced NADPH oxidase activity [77]. A group of workers have demonstrated the benefits of pitavastatin administration in Dahl salt-sensitive rats. Pitavastatin showed promising results as it protected podocyte injury, mainly by inhibiting the angiotensin type I receptor (AT1R)-induced NADPH oxidase activity [78].

\section{Antidiabetic drugs}

Preferring some antidiabetic drugs over the others can be an interesting and useful treatment option for DN. This treatment option can have two-fold benefits as it only not provides better glycemic control but also provides renoprotection against oxidative stress-induced damage. The first antidiabetic drug that deserves to be mentioned is rapamycin. It has been shown to decrease oxidative stress and improve the function of antioxidant enzymes, such as glutathione 
[79-80]. Researchers have evaluated the effects of rapamycin administration on rats with experimentally induced DN. Results showed that administration of rapamycin reduced the activity of NADPH oxidase and improved the density of podocytes by inhibiting their apoptosis [81]. Another drug in the antidiabetic category that might make a good addition for the treatment of DN is metformin. The antioxidant potential of metformin is multidimensional. It reduces oxidative stress [82], up-regulates the level of glutathione [83], and suppresses the activity of NADPH oxidase [84]. Results from several studies have persistently supported the benefit of metformin in DN. Metformin decreases oxidative stress through several mechanisms, mainly through the suppression of NADPH oxidase, and by improving the density and functioning of podocytes [85-88].

\section{Antioxidant vitamins}

Among vitamins, the vitamins that might be useful in the treatment of DN include antioxidant vitamins like vitamins C, D, and E. Vitamin D is a well-known antioxidant [89] and inhibitor of NADPH oxidase [90]. Several studies have shown the efficacy of vitamin D in saving podocytes from oxidative stress, mainly due to its antioxidant action [91-93]. Other antioxidant vitamins that might help uplift the health of podocytes include alpha-tocopherol and ascorbic acid. It has been demonstrated that co-administration of puromycin, a known reno-toxic drug, and alpha-tocopherol/ascorbic acid can help decrease podocyte damage and increase podocyte density [94]. The efficacy of these vitamins in relation to DN has not yet been elucidated. The evaluation of benefits of these antioxidant vitamins in DN demands further research.

\section{Conclusions}

Podocyte injury represents a centripetal event in the progression of DN and related functional deficits like microalbuminuria and decreased GFR. NAPDH oxidase-mediated oxidative stress seems to be the most important event in the oxidative podocyte injury. Increased production of ROS then inflicts serious damage to the podocytes and leads to slowly progressing deterioration in kidney structure and function. Thus, blocking the production of ROS can be a valuable treatment approach for decreasing podocyte injury and resultant kidney disease. In the light of current literature, we have concluded that certain NADPH oxidase inhibitors, RAAS inhibitors, statins, antidiabetic drugs, and antioxidant vitamins have shown significant potential in decreasing oxidation-induced podocyte injury. These therapeutic agents have shown positive results in animal models of $\mathrm{DN}$, but clinical trials to see their effects on humans are rather lacking. There is a need for research and clinical trials using these therapeutic agents to study their efficacy for managing DN.

\section{Additional Information \\ Disclosures}

Conflicts of interest: In compliance with the ICMJE uniform disclosure form, all authors declare the following: Payment/services info: All authors have declared that no financial support was received from any organization for the submitted work. Financial relationships: All authors have declared that they have no financial relationships at present or within the previous three years with any organizations that might have an interest in the submitted work. Other relationships: All authors have declared that there are no other relationships or activities that could appear to have influenced the submitted work.

\section{References}

1. American Diabetes Association: Diagnosis and classification of diabetes mellitus. Diabetes Care. 2010, 33:S62-S69. 10.2337/dc10-S062

2. Alberti KG, Zimmet PZ: Definition, diagnosis and classification of diabetes mellitus and its 
complications. Part 1: diagnosis and classification of diabetes mellitus provisional report of a WHO consultation. Diabet Med. 1998, 15:539-53. 10.1002/(SICI)1096-

9136(199807)15:7<539::AID-DIA668>3.0.CO;2-S

3. IDF Diabetes atlas - Key findings 2014 . (2014). Accessed: October 30, 2015:

https://www.idf.org/diabetesatlas/update-2014.

4. Murphy D: Acute complications of diabetes mellitus . Nurse Pract Forum. 1998, 9:69-73.

5. Nalysnyk L, Hernandez-Medina M, Krishnarajah G: Glycaemic variability and complications in patients with diabetes mellitus: evidence from a systematic review of the literature. Diabetes Obes Metab. 2010, 12:288-98. 10.1111/j.1463-1326.2009.01160.x

6. Forbes JM, Cooper ME: Mechanisms of diabetic complications. Physiol Rev. 2013, 93:137-88. 10.1152/physrev.00045.2011

7. van Dieren S, Beulens JW, van der Schouw YT, Grobbee DE, Neal B: The global burden of diabetes and its complications: an emerging pandemic. Eur J Cardiovasc Prev Rehabil. 2010, 17:S3-8. 10.1097/01.hjr.0000368191.86614.5a

8. Bailes BK: Diabetes mellitus and its chronic complications . AORN J. 2002, 76:266-82. 10.1016/S0001-2092(06)61065-X

9. Reutens AT, Atkins RC: Epidemiology of Diabetic Nephropathy. Diabetes and the Kidney. Lai KN, Tang SCW (ed): Karger Publishers, Switzerland; 2011. 170:1-7. 10.1159/000324934

10. Rychlík I: Epidemiology of diabetic nephropathy (Article in Czech) . Vnitr Lek. 2008, 54:48893.

11. Gross JL, de Azevedo MJ, Silveiro SP, Canani LH, Caramori ML, Zelmanovitz T: Diabetic nephropathy: diagnosis, prevention, and treatment. Diabetes Care. 2005, 28:164-76. 10.2337/diacare.28.1.164

12. Zelmanovitz T, Gerchman F, Balthazar AP, Thomazelli FC, Matos JD, Canani LH.: Diabetic nephropathy. Diabetol Metab Syndr. 2009, 1:10. 10.1186/1758-5996-1-10

13. Goode NP, Shires M, Crellin DM, Aparicio SR, Davison AM: Alterations of glomerular basement membrane charge and structure in diabetic nephropathy. Diabetologia. 1995, 38:1455-65. 10.1007/BF00400607

14. Østeeby R: Morphometric studies of the peripheral glomerular basement membrane in early juvenile diabetes I. Development of initial basement membrane thickening. Diabetologia. 1972, 8:84-92. 10.1007/BF01235631

15. Brito PL, Fioretto P, Drummond K, Kim Y, Steffes MW, Basgen JM, Sisson-Ross S, Mauer M: Proximal tubular basement membrane width in insulin-dependent diabetes mellitus . Kidney Int. 1998, 53:754-61. 10.1046/j.1523-1755.1998.00809.x

16. Fioretto P, Steffes MW, Mauer M: Glomerular structure in non-proteinuric insulin-dependent diabetic patients with various levels of albuminuria. Diabetes. 1994, 43:1358-64.

10.2337/diab.43.11.1358

17. Mauer SM, Steffes MW, Ellis EN, Sutherland DE, Brown DM, Goetz FC: Structural functional relationships in diabetic nephropathy. J Clin Invest. 1984, 74:1143-55. 10.1172/JCI111523

18. Harris RD, Steffes MW, Bilous RW, Sutherland DE, Mauer SM: Global glomerular sclerosis and glomerular arteriolar hyalinosis in insulin-dependent diabetes. Kidney Int. 1991, 40:107-14. 10.1038/ki.1991.187

19. Najafian B, Kim Y, Crosson JT, Mauer M: Atubular glomeruli and glomerulotubular junction abnormalities in diabetic nephropathy. J Am Soc Nephrol. 2003, 14:908-17.

10.1097/01.ASN.0000057854.32413.81

20. Najafian B, Crosson JT, Kim Y, Mauer M: Glomerulotubular junction abnormalities are associated with proteinuria in type 1 diabetes. J Am Soc Nephrol. 2006, 17:S53-60. 10.1681/ASN.2005121342

21. Fioretto P, Mauer M: Histopathology of diabetic nephropathy. Semin Nephrol. 2007, 27:195207.10.1016/j.semnephrol.2007.01.012

22. de Zeeuw D, Remuzzi G, Parving HH, Keane WF, Zhang Z, Shahinfar S, Snapinn S, Cooper ME, Mitch WE, Brenner BM: Proteinuria, a target for renoprotection in patients with type 2 diabetic nephropathy: lessons from RENAAL. Kidney Int. 2004, 65:2309-20. 10.1111/j.15231755.2004.00653.x

23. Drummond K, Mauer M; International Diabetic Nephropathy Study Group: International Diabetic Nephropathy Study Group. The early natural history of nephropathy in type 1 diabetes. II. Early renal structural changes in type 1 diabetes. Diabetes. 2002, 51:1580-87. 10.2337/diabetes.51.5.1580 
24. Pagtalunan ME, Miller PL, Jumping-Eagle S, Nelson RG, Myers BD, Rennke HG, Coplon NS, Sun L, Meyer TW: Podocyte loss and progressive glomerular injury in type II diabetes . J Clin Invest. 1997, 99:342-48. 10.1172/JCI119163

25. Meyer TW, Bennett PH, Nelson RG: Podocyte number predicts long-term urinary albumin excretion in Pima Indians with type II diabetes and microalbuminuria. Diabetologia. 1999, 42:1341-44. 10.1007\%2Fs001250051447

26. Wolf G, Chen S, Ziyadeh FN: From the periphery of the glomerular capillary wall toward the center of disease: podocyte injury comes of age in diabetic nephropathy. Diabetes. 2005, 54:1626-34. 10.2337/diabetes.54.6.1626

27. Steffes MW, Schmidt D, McCrery R, Basgen JM; International Diabetic Nephropathy Study Group: Glomerular cell number in normal subjects and in type 1 diabetic patients . Kidney Int. 2001, 59:2104-13. 10.1046/j.1523-1755.2001.00725.x

28. Susztak K, Raff AC, Schiffer M, Böttinger EP: Glucose-induced reactive oxygen species cause apoptosis of podocytes and podocyte depletion at the onset of diabetic nephropathy.

Diabetes. 2006, 55:225-33. 10.2337/diabetes.55.01.06.db05-0894

29. Dalla Vestra M, Masiero A, Roiter AM, Saller A, Crepaldi G, Fioretto P: Is podocyte injury relevant indiabetic nephropathy? Studies in patients with type 2 diabetes. Diabetes. 2003, 52:1031-35. 10.2337/diabetes.52.4.1031

30. Chung SS, Ho EC, Lam KS, Chung SK: Contribution of polyol pathway to diabetes-induced oxidative stress. J Am Soc Nephrol. 2003, 14:S233-36. 10.1097/01.ASN.0000077408.15865.06

31. Forbes JM, Cooper ME, Oldfield MD, Thomas MC: Role of advanced glycation end products in diabetic nephropathy. J Am Soc Nephrol. 2003, 14:S254-58.

10.1097/01.ASN.0000077413.41276.17

32. Yamagishi S, Matsui T: Advanced glycation end products, oxidative stress and diabetic nephropathy. Oxid Med Cell Longev. 2010, 3:101-8. 10.4161/oxim.3.2.11148

33. Li J, Gobe G: Protein kinase C activation and its role in kidney disease . Nephrology (Carlton). 2006, 11:428-34. 1 0.1111/j.1440-1797.2006.00673.x

34. Yu X, Schiffer M: Role of protein kinase C in podocytes and development of glomerular damage in diabetic nephropathy. Front Endocrinol (Lausanne). 2014, 5:179.

10.3389/fendo.2014.00179

35. Ha H, Lee HB: Reactive oxygen species amplify glucose signaling in renal cells cultured under high glucose and in diabetic nephropathy. Nephrology (Carlton). 2005, 10:S7-10. 10.1111/j.1440-1797.2005.00448.x

36. Lee HB, Yu MR, Yang Y, Jiang Z, Ha H: Reactive oxygen species-regulated signaling pathways in diabetic nephropathy. J Am Soc Nephrol. 2003, 14:S241-45.

10.1097/01.ASN.0000077410.66390.0F

37. Brownlee M: Advanced protein glycosylation in diabetes and aging . Annu Rev Med. 1995, 46:223-34. 10.1146/annurev.med.46.1.223

38. Jandeleit-Dahm K, Cooper ME: Hypertension and diabetes: role of renin-angiotensin system. Endocrinol Metab Clin N Am. 2006, 35:469-90. 10.1016/j.ecl.2006.06.007

39. Shibata S, Nagase M, Yoshida S, Kawachi H, Fujita T: Podocyte as the target for aldosterone: roles of oxidative stress and Sgk1. Hypertension. 2007, 49:355-64. 10.1161/01.HYP.0000255636.11931.a2

40. Velez JC, Bland AM, Arthur JM, Raymond JR, Janech MG: Characterization of reninangiotensin system enzyme activities in cultured mouse podocytes. Am J Physiol Renal Physiol. 2007, 293:F398-407. 10.1152/ajprenal.00050.2007

41. Griendling KK, Ushio-Fukai M: Reactive oxygen species as mediators of angiotensin II signaling. Regul Pept. 2000, 91:21-27. 10.1016/S0167-0115(00)00136-1

42. Whaley-Connell AT, Chowdhury NA, Hayden MR, Stump CS, Habibi J, Wiedmeyer CE, Gallagher PE, Tallant EA, Cooper SA, Link CD, Ferrario C, Sowers JR: Oxidative stress and glomerular filtration barrier injury: role of the renin-angiotensin system in the Ren2 transgenic rat. Am J Physiol Renal Physiol. 2006, 291:F1308-F1314.

10.1152/ajprenal.00167.2006

43. Circu ML, Aw TY: Reactive oxygen species, cellular redox system and apoptosis . Free Radic Biol Med. 2010, 48:749-62. 10.1016/j.freeradbiomed.2009.12.022

44. Greiber S, Münzel T, Kästner S, Müller B, Schollmeyer P, Pavenstädt H: NAD(P)H oxidase activity in cultured human podocytes: effects of adenosine triphosphate. Kidney Int. 1998, 53:654-63. 10.1046/j.1523-1755.1998.00796.x 
45. Kanwar YS, Sun L, Xie P, Liu FY, Chen S: A glimpse of various pathogenetic mechanisms of diabetic nephropathy. Annu Rev Pathol. 2011, 6:395-423.

10.1146/annurev.pathol.4.110807.092150

46. Eid AA, Gorin Y, Fagg BM, Maalouf R, Barnes JL, Block K, Abboud HE: Mechanisms of podocyte injury in diabetes: role of cytochrome P450 and NADPH oxidases. Diabetes. 2009, 58:1201-11. 10.2337/db08-1536

47. Susztak K, Raff AC, Schiffer M, Böttinger EP: Glucose-induced reactive oxygen species cause apoptosis of podocytes and podocyte depletion at the onset of diabetic nephropathy. Diabetes. 2006, 55:225-33. 10.2337/diabetes.55.01.06.db05-0894

48. Gorin Y, Block K, Hernandez J, Bhandari B, Wagner B, Barnes JL, Abboud HE: Nox4 NAD(P)H oxidase mediates hypertrophy and fibronectin expression in the diabetic kidney. J Biol Chem. 2005, 280:39616-26. 10.1074/jbc.M502412200

49. Kim NH, Rincon-Choles H, Bhandari B, Choudhury GG, Abboud HE, Gorin Y: Redox dependence of glomerular epithelial cell hypertrophy in response to glucose. Am J Physiol Renal Physiol. 2006, 290:F741-51. 10.1152/ajprenal.00313.2005

50. Li JM, Shah AM: ROS generation by nonphagocytic NADPH oxidase: potential relevance in diabetic nephropathy. J Am Soc Nephrol. 2003, 14:S221-26. 10.1097/01.ASN.0000077406.67663.E7

51. Wu F, Wilson JX: Triptolide inhibits NADPH oxidase activity and iNOS expression in LPS+IFN gamma-stimulated microvascular endothelial cells. The FASEB Journal. 2007, 21:550.12.

52. Chen ZH, Qin WS, Zeng CH, Zheng CX, Hong YM, Lu YZ, Li LS, Liu ZH: Triptolide reduces proteinuria in experimental membranous nephropathy and protects against C5b-9-induced podocyte injury in vitro. Kidney Int. 2010, 77:974-88. 10.1038/ki.2010.41

53. Meng R, Zhu DL, Bi Y, Yang DH, Wang YP: Anti-oxidative effect of apocynin on insulin resistance in high-fat diet mice. Ann Clin Lab Sci. 2011 , 41:236-43.

54. Kinugasa S, Tojo A, Sakai T, Tsumura H, Takahashi M, Hirata Y, Fujita T: Selective albuminuria via podocyte albumin transport in puromycin nephrotic rats is attenuated by an inhibitor of NADPH oxidase. Kidney Int. 2011, 80:1328-38. 10.1038/ki.2011.282

55. Wang Z, Wei X, Zhang Y, Ma X, Li B, Zhang S, Du P, Zhang X, Yi F: NADPH oxidase-derived ROS contributes to upregulation of TRPC6 expression in puromycin aminonucleoside-induced podocyte injury. Cell Physiol Biochem. 2009, 24:619-26. 10.1159/000257517

56. Kinkade K, Streeter J, Miller FJ: Inhibition of NADPH oxidase by apocynin attenuates progression of atherosclerosis. Int J Mol Sci. 2013, 14: 17017-28. 10.3390/ijms140817017

57. Winiarska K, Focht D, Sierakowski B, Lewandowski K, Orlowska M, Usarek M: NADPH oxidase inhibitor, apocynin, improves renal glutathione status in Zucker diabetic fatty rats: a comparison with melatonin. Chem Biol Interact. 2014, 218:12-19. 10.1016/j.cbi.2014.04.005

58. Tazzeo T, Worek F, Janssen L: The NADPH oxidase inhibitor diphenyleneiodonium is also a potent inhibitor of cholinesterases and the internal Ca2+ pump. Br J Pharmacol. 2009, 158:790-96. 10.1111/j.1476-5381.2009.00394.x

59. Abais JM, Zhang C, Xia M, Liu Q, Gehr TW, Boini KM, Li PL: NADPH oxidase-mediated triggering of inflammasome activation in mouse podocytes and glomeruli during hyperhomocysteinemia. Antioxid Redox Signal. 2013, 18:1537-48. 10.1089/ars.2012.4666

60. Wind S, Beuerlein K, Eucker T, Müller H, Scheurer P, Armitage ME, Ho H, Schmidt HH, Wingler K: Comparative pharmacology of chemically distinct NADPH oxidase inhibitors . Br J Pharmacol. 2010, 161:885-98. 10.1111/j.1476-5381.2010.00920.x

61. Vendrov AE, Madamanchi NR, Niu XL, Molnar KC, Runge M, Szyndralewiez C, Page P, Runge MS: NADPH oxidases regulate CD44 and hyaluronic acid expression in thrombin-treated vascular smooth muscle cells and in atherosclerosis. J Biol Chem. 2010, 285:26545-57. 10.1074/jbc.M110.143917

62. Laleu B, Gaggini F, Orchard M, Fioraso-Cartier L, Cagnon L, Houngninou-Molango S, Gradia A, Duboux G, Merlot C, Heitz F, Szyndralewiez C, Page P: First in class, potent, and orally bioavailable NADPH oxidase isoform 4 (Nox4) inhibitors for the treatment of idiopathic pulmonary fibrosis. J Med Chem. 2010, 53:7715-30. 10.1021/jm100773e

63. Onuigbo MA: Analytical review of the evidence for renoprotection by renin-angiotensinaldosterone system blockade in chronic kidney disease - A call for caution. Nephron Clin Pract. 2009, 113:c63-c70. 10.1159/000228536

64. Campbell KN, Raij L, Mundel P: Role of angiotensin II in the development of nephropathy and podocytopathy of diabetes. Curr Diabetes Rev. 2011, 7:3-7. 
10.2174/157339911794273973\#sthash.vnatP81Z.dpuf

65. Todd PA, Heel RC: Enalapril. A review of its pharmacodynamic and pharmacokinetic properties, and therapeutic use in hypertension and congestive heart failure. Drugs. 1986, 31:198-248. 10.2165/00003495-198631030-00002

66. de Cavanagh EM, Inserra F, Toblli J, Stella I, Fraga CG, Ferder L: Enalapril attenuates oxidative stress in diabetic rats. Hypertension. 2001, 38:1130-36. 10.1161/hy1101.092845

67. Taye A, Morawietz H: Spironolactone inhibits NADPH oxidase-induced oxidative stress and enhances eNOS in human endothelial cells. Iran J Pharm Res. 2011, 10:329-37.

68. Dăneasă A, Cucolaș C, Furcea M, Bolfa P, Dudea S, Olteanu D, Alupei MC, Mureșan A, Filip GA: Spironolactone and dimethylsulfoxide effect on glucose metabolism and oxidative stress markers in polycystic ovarian syndrome rat model. Exp Clin Endocrinol Diabetes. 2014, 122:154-62. 10.1055/s-0033-1363685

69. Toyonaga J, Tsuruya K, Ikeda H, Noguchi H, Yotsueda H, Fujisaki K, Hirakawa M, Taniguchi M, Masutani K, Iida M: Spironolactone inhibits hyperglycemia-induced podocyte injury by attenuating ROS production. Nephrol Dial Transplant. 2011, 26:2475-84. 10.1093/ndt/gfq750

70. Fortuño A, Bidegain J, Robador PA, Hermida J, López-Sagaseta J, Beloqui O, Díez J, Zalba G: Losartan metabolite EXP3179 blocks NADPH oxidase-mediated superoxide production by inhibiting protein kinase C: potential clinical implications in hypertension. Hypertension. 2009, 54:744-50. 10.1161/HYPERTENSIONAHA.109.129353

71. Mehdi UF, Adams-Huet B, Raskin P, Vega GL, Toto RD: Addition of angiotensin receptor blockade or mineralocorticoid antagonism to maximal angiotensin-converting enzyme inhibition in diabetic nephropathy. J Am Soc Nephrol. 2009, 20:2641-50. 10.1681/ASN.2009070737

72. Manea A: NADPH oxidase-derived reactive oxygen species: involvement in vascular physiology and pathology. Cell Tissue Res. 2010, 342:325-39. 10.1007/s00441-010-1060-y

73. Davignon J, Jacob RF, Mason RP: The antioxidant effects of statins . Coron Artery Dis. 2004, 15:251-58. 10.1097/01.mca.0000131573.31966.34

74. Stoll LL, McCormick ML, Denning GM, Weintraub NL: Antioxidant effects of statins . Drugs Today (Barc). 2004, 40:975-90. 10.1358/dot.2004.40.12.872573

75. Shishehbor MH, Brennan ML, Aviles RJ, Fu X, Penn MS, Sprecher DL, Hazen SL: Statins promote potent systemic antioxidant effects through specific inflammatory pathways. Circulation. 2003, 108:426-31. 10.1161/01.CIR.0000080895.05158.8B

76. Broncel M, Koter-Michalak M, Chojnowska-Jezierska J: The effect of statins on lipids peroxidation and activities of antioxidants enzymes in patients with dyslipidemia (Article in Polish). Przegl Lek. 2006, 63:738-42.

77. Whaley-Connell A, DeMarco VG, Lastra G, Manrique C, Nistala R, Cooper SA, Westerly B, Hayden MR, Wiedmeyer C, Wei Y, Sowers JR: Insulin resistance, oxidative stress, and podocyte injury: role of rosuvastatin modulation of filtration barrier injury. Am J Nephrol. 2008, 28:67-75. 10.1159/000109394

78. Cheng XW, Kuzuya M, Sasaki T, Inoue A, Hu L, Song H, Huang Z, Li P, Takeshita K, Hirashiki A, Sato K, Shi GP, Okumura K, Murohara T: Inhibition of mineralocorticoid receptor is a renoprotective effect of the 3-hydroxy-3-methylglutaryl-coenzyme A reductase inhibitor pitavastatin. J Hypertens. 2011, 29:542-52. 10.1097/HJH.0b013e328341cedf

79. Das A, Durrant D, Koka S, Salloum FN, Xi L, Kukreja R: Mammalian target of rapamycin (mTOR) inhibition with rapamycin improves cardiac function in type 2 diabetic mice: potential role of attenuated oxidative stress and altered contractile protein expression. J Biol Chem. 2014, 289:4145-60. 10.1074/jbc.M113.521062

80. Marobbio CM, Pisano I, Porcelli V, Lasorsa FM, Palmieri L: Rapamycin reduces oxidative stress in frataxin-deficient yeast cells. Mitochondrion. 2012 , 12:156-61. 10.1016/j.mito.2011.07.001

81. Eid AA, Ford BM, Bhandary B, de Cassia Cavaglieri R, Block K, Barnes JL, Gorin Y, Choudhury GG, Abboud HE: Mammalian target of rapamycin regulates Nox4-mediated podocyte depletion in diabetic renal injury. Diabetes. 2013, 62:2935-47. 10.2337/db12-1504

82. Esteghamati A, Eskandari D, Mirmiranpour H, Noshad S, Mousavizadeh M, Hedayati M, Nakhjavani M: Effects of metformin on markers of oxidative stress and antioxidant reserve in patients with newly diagnosed type 2 diabetes: a randomized clinical trial. Clin Nutr. 2013, 32:179-85. 10.1016/j.clnu.2012.08.006

83. Ewis SA, Abdel-Rahman MS: Effect of metformin on glutathione and magnesium in normal and streptozotocin-induced diabetic rats. J Appl Toxicol. 1995, 15:387-90. 


\subsection{2/jat.2550150508}

84. Piwkowska A, Rogacka D, Jankowski M, Dominiczak MH, Stepiński JK, Angielski S: Metformin induces suppression of NAD(P)H oxidase activity in podocytes. Biochem Biophys Res Commun. 2010, 393:268-73. 10.1016/j.bbrc.2010.01.119

85. Kim J, Shon E, Kim C-S, et al: Renal podocyte injury in a rat model of type 2 diabetes is prevented by metformin. Exp Diabetes Res. 2012, 2012:ID: 210821. 10.1155/2012/210821

86. Rafieian-Kopaie M: Metformin and renal injury protection. J Renal Inj Prev. 2013, 2:91-92. 10.12861/jrip.2013.29

87. Nasri RH: Renoprotective effects of metformin. Daru. 2013, 21:36. 10.1186/2008-2231-21-36

88. Piwkowska A, Rogacka D, Jankowski M, Angielski S: Metformin reduces NAD(P)H oxidase activity in mouse cultured podocytes through purinergic dependent mechanism by increasing extracellular ATP concentration. Acta Biochim Pol. 2013, 60:607-12.

89. Wiseman H: Vitamin D is a membrane antioxidant Ability to inhibit iron-dependent lipid peroxidation in liposomes compared to cholesterol, ergosterol and tamoxifen and relevance to anticancer action. FEBS Lett. 1993, 326:285-88. 10.1016/0014-5793(93)81809-E

90. Kassi E, Adamopoulos C, Basdra EK, Papavassiliou AG: Role of Vitamin D in atherosclerosis . Circulation. 2013, 128:2517-31. 10.1161/CIRCULATIONAHA.113.002654

91. Zhang X, Song Z, Guo Y, Zhou M: The novel role of TRPC6 in vitamin D ameliorating podocyte injury in STZ-induced diabetic rats. Mol Cell Biochem. 2015, 399:155-65. 10.1007/s11010014-2242-9

92. Zhang XL, Guo YF, Song ZX, Zhou M: Vitamin D prevents podocyte injury via regulation of macrophage M1/M2 phenotype in diabetic nephropathy rats. Endocrinology. 2014, 155:493950. 10.1210/en.2014-1020

93. Sonneveld R, Ferrè S, Hoenderop JG, Dijkman HB, Berden JH, Bindels RJ, Wetzels JF, van der Vlag J, Nijenhuis T: Vitamin D down-regulates TRPC6 expression in podocyte injury and proteinuric glomerular disease. Am J Pathol. 2013, 182:1196-204. 10.1016/j.ajpath.2012.12.011

94. Ricardo SD, Bertram JF, Ryan GB: Antioxidants protect podocyte foot processes in puromycinaminonucleoside-treated rats. J Am Soc Nephrol. 1994, 4:1974-86. 